\title{
La guerra hispano-norteamericana en la prensa checa de fines del siglo XIX *
}

\author{
Josef Opatrný \\ Universidad Carolina, Praga \\ República Checa
}

\begin{abstract}
El estudio esboza el panorama de las opiniones de los periódicos checos más importantes sobre la guerra hispano-norteamericana incluidos los periódicos publicados por la numerosa emigración checa en los Estados Unidos. Para los periodistas checos, la guerra no era objeto de un interés económico o político directo; no obstante, servía como una oportunidad de presentar su postura a un nivel ideológico general. Los liberales apoyaban a los Estados Unidos presentándolos como defensores del derecho a la lucha por la libertad nacional. España tuvo, por el contrario, las simpatías de la prensa católica que defendía las tradiciones y la religión de este país. La prensa del movimiento obrero, po su parte, criticaba la guerra que perjudicaba los intereses de la mayoría de la sociedad, ofreciendo ganancias solamente al capital.
\end{abstract}

Al menos para tres naciones, esta guerra hispano-americana representa uno de los momentos más importantes en el desarrollo de la sociedad nacional y los historiadores la analizan desde muchos ángulos. En Cuba, en los Estados Unidos y en España se publicaron centenares de libros (por no hablar de artículos) sobre este evento que hasta un grupo de los historiadores marxistas consideraba como uno de los acontecimientos claves de la historia universal. ${ }^{1}$ Una parte de los historiadores presenta la guerra como fruto de las actividades de los periodistas ${ }^{2} \mathrm{y}$, por eso, no sorprende mucho que existan estudios especializados dedicados a la prensa de ambas partes beligerantes. ${ }^{3}$ Es también la prensa la que ofrece las opiniones en lo refe-

* Este artículo fue escrito como una parte del proyecto no. 404/95/0195 de Agencia Grant de la República Checa y presentado en el XI Congreso Internacional de AHILA, Liverpool, 17-22 de septiembre de 1996. Nota aclaratoria de la revista: en el título se ha usado la palabra "norteamericana" para evitar confusiones, manteniéndose en el texto la palabra "americana" usada por el autor.

1 Los teóricos del marxismo la llamaron una de las primeras guerras de la época imperialista y desde entonces decenas de historiadores han subrayado la importancia clave de este conflicto para el proceso histórico en el mundo. En este contexto ver Wolfe, Patrick: "Imperialism and History: A Century of Theory, from Marx to Postcolonialism", en: The American Historical Review, vol. 102, n. ${ }^{\circ}$, April 1997, págs. 388-420.

2 Comp. en este contexto ante todo el libro con un título característico de Brown, Charles: The Correspondents War. Journalists in the Spanish-American War, New York, 1967.

3 Comp., por ejemplo, Wisan, Joseph A: The Cuban Crisis as Reflected in the New York Press, New York, 1934; Linderman, Gerald F.: The Mirror of War. American Society and the SpanishAmerican War, Ann Arbor, 1974 o Sevilla Soler, Rosario: La guerra de Cuba y la memoria colectiva: la crisis del 98 en la prensa sevillana, Sevilla, 1996. 
rente a la guerra hispano-americana por parte de aquellas sociedades que no tenían ningún interés directo en los acontecimientos en Cuba, las Filipinas y Puerto Rico.

A pesar de que los países checos formaban parte a fines del siglo XIX del imperio austro-húngaro, se interesaron en el conflicto entre España y los Estados Unidos; ${ }^{4}$ la propia sociedad checa tenía otras prioridades antes que la tensión creciente en la región caribeña, ya que fue un tiempo de luchas feroces entre los checos y los alemanes, y de intentos incesantes de los primeros por obtener algunos derechos en la esfera cultural y política. Sin embargo, curiosamente, estas tensiones entre los portavoces de la sociedad checa y el gobierno en Viena fueron una de las razones del interés de la prensa checa por los acontecimientos que ocurrían en el mundo hispanohablante: la parte "nacional" de la prensa atacaba la política oficial austríaca por su apoyo de España. ${ }^{5}$

Otro motivo era, sin duda, el interés de los productores checos de azúcar de remolacha. Además, los países checos pertenecían a las regiones más desarrolladas de Europa, y producían maquinaria para las fábricas de azúcar y, por eso, la sociedad checa sabía algo sobre Cuba. Muchos de los artículos que en ese tiempo mencionaban la colonia española, la presentaban como el primer productor mundial de azúcar de caña. Antes de finalizar el siglo, aparecieron ya en las centrales de Cuba los técnicos checos y este hecho demuestra los contactos prácticos entre ambos países. ${ }^{6}$ No obstante, es verdad que en el año 1898 prevalecieron en la prensa checa las informaciones sobre la inminente guerra entre los Estados Unidos y España. ${ }^{7}$ Tan sólo excepcionalmente los periódicos checos tuvieron sus corresponsales directos en los países beligerantes; ese fue el caso de Národní listy ( $E l$ Diario Nacional), con un corresponsal en Madrid y en Chicago. Como fuentes de información sirvieron en la mayoría de los casos las noticias de

4 Sobre el contexto internacional de la guerra hispano-americana véase ante todo Vladimirov, L. S.: Diplomatija S ŠA v period amerikansko-ispanskoj vojny, Moskva, 1957.

5 Es, sin embargo, interesante que precisamente en los años ochenta y noventa apareciera en la sociedad culta checa el interés por la cultura española como lo demuestra, por ejemplo, el libro de Pinkas, Ota: Cesta po Š́anéich (Viaje a España), Praha, 1880, o las traducciones de la literatura clásica española llevadas a cabo por los mejores artistas checos de la época, que buscaban el modo de cómo liquidar la dependencia de la cultura checa de las fuentes tradicionales - es decir, ante todo de la literatura de habla alemana y, en menor medida, de la francesa o italiana.

6 Sobre esta problemática ver Schejbal, Jan: "Los especialistas azucareros en Cuba y España alrededor de 1900”, Ibero-Americana Pragensia, vol. XIV, Praga 1980, págs. 155-167.

7 El primero que estudió esta problemática fue Polišnský, Josef: "Guerra hispano-americana de 1898 y la opinión pública checa”, Historica, VII, Praga, 1963, págs. 99-113. 
grandes agencias y de periódicos extranjeros - ante todo alemanes pero también franceses, ingleses y americanos - ${ }^{8}$ y con cierto retraso los periódicos que numerosos editores checos publicaban en los Estados Unidos para los emigrantes de procedencia checa, ante todo en la parte oriental y centrooccidental de aquel país. ${ }^{9}$ Analizaremos las opiniones de esos "checo-americanos" en la segunda parte de este artículo.

Los años finales del siglo XIX significaron en Bohemia un período de cambios sustanciales en la escena política, donde los partidos tradicionales de "staročěš" (los checos viejos) y "mladočeš" (los checos jóvenes) iban perdiendo lentamente sus posiciones, mientras progresaban partidos nuevos, encabezados por el partido socialdemócrata. Apareció también un grupo muy pequeño, pero influyente, de intelectuales - los realistas - cuyo portavoz Tomáš Garrigue Masaryk llegó a ser una de las personalidades más destacadas de la sociedad checa. El tiempo de los cambios y de la modernización de esa sociedad, no solamente en el sentido de introducción de técnicas y tecnologías nuevas, sino ante todo en lo referente a las relaciones entre diferentes capas sociales y a su lugar en la vida política, en la cultura, etc., influyó también en los tradicionalistas cuyo programa era la defensa de las tradiciones, ante todo religiosas y que se agruparon en varios partidos católicos. Esa situación nueva, compleja ya en sí misma, la complicó aún más la existencia de una numerosa entidad de habla alemana en Praga y en algunas regiones más del país. ${ }^{10}$

Todos esos partidos, grupos y corrientes se esforzaban por poder presentar sus opiniones en la prensa. Algunos partidos tenían sus propios órganos de expresión, como fue el caso del partido socialdemócrata y su periódico Právo lidu (El derecho del Pueblo). Otros periódicos simpatizaban con ciertos partidos o políticos, colaborando a veces con los portavoces de dichos partidos. De tal manera, Katolické listy (El Periódico Católico) expresaba las opiniones no solamente del partido católico, sino también de

8 Ya desde los años sesenta existió en Praga un centro de aficionados a la cultura americana agrupados alrededor de la famosa persona de los círculos culturales checos, Vojta Náprstek, contando con una pequeña biblioteca provista de periódicos estadounidenses; para más, ver ante todo Šlle, Zdenèk: Vojta Náprstek a jeho doba (Vojta Náprstek y su tiempo), Praha, 1994.

9 Sobre esta emigración y su prensa está la obra clásica de Cápek, Tomáš: Nǎ̌ Amerika (Nuestra América), Praha, 1926.

10 A pesar de la vasta bibliografía sobre la problemática de las diferentes corrientes políticas en la Bohemia del siglo XIX, se repiten siempre grandes discusiones sobre este tema. Como introducción al problema comp. esp. los estudios del investigador checo Urban, Otto: Kapitalismus a čská společnost (El capitalismo y la sociedad checa), Praha, 1978, y, el mismo Č́ská společnost 1848-1918, (La sociedad checa de 1848-1918), Praha, 1982. 
los grupos simpatizantes con el catolicismo. Los periódicos que gozaban probablemente de la mayor repercusión en la sociedad checa se encontraban, respectivamente, "cerca" de los checos jóvenes - esto fue el caso de Národní listy—y de los checos viejos —Politik (Política) — cuyas opiniones repetía muchas veces el periódico quizás más popular y de circulación muy amplia, a saber Národní politika (La Política Nacional), diario conservador leído por la capa media, mientras que Politik, publicado en alemán, encontró sus lectores en la capa media alta. Los autores de las noticias, comentarios, etc., no sólo presentaban sus opiniones sobre los acontecimientos en Cuba o en las Filipinas, sino que aprovechaban muy a menudo la oportunidad para atacar a sus adversarios políticos nacionales o para expresar sus consideraciones más generales.

En este sentido, los socialdemócratas checos adoptaron una postura típica. Rechazaron la guerra como un medio de enriquecimiento de la burguesía y de empobrecimiento de las capas trabajadoras:

"La guerra traerá la subida de los precios también en Europa. Los americanos y los españoles van a asesinar y los capitalistas van a llenarse las bolsas. Les interesa solamente la ganancia y nadie les impedirá liquidar a la gente trabajadora". ${ }^{11}$

No obstante, comparando la política de los Estados Unidos y de España y analizando las causas del conflicto, el autor del artículo "Rozvrat ve Španèlsku" ("Perturbaciones en España") escribió:

"Nunca creímos en el idealismo de los yankees. Preguntando por las causas de la guerra, debemos contestar con justeza. Fue la política colonial española la que causó la catástrofe. A lo largo de tres años, los americanos observaron tranquilamente la destrucción y los asesinatos en Cuba, otras naciones quizás no pudieran soportar tal situación durante tanto tiempo. Cualesquiera sean los móviles de los norteamericanos, su intervención podría solamente mejorar la situación de las colonias torturadas por España, al menos por un momento. Qué ocurrirá después, es una pregunta seria, hay que esperar la evolución de las cosas". ${ }^{12}$

Según el autor anónimo del artículo, todo el asunto demuestra que la cruel explotación no aportó nada a España. La sublevación de los cubanos y la guerra sirvieron de ejemplo para demostrar que el Estado debe fun-

11 "Loupežné tažení kapitalistư" ("La campaña de rapiña de los capitalistas”), Právo lidu, vol. VII, n. ${ }^{\circ} 110,21$ de abril de 1898 , pág. 1.

12 "Rozvrat ve Španèlsku" ("Las perturbaciones en España"), Ibídem, n. ${ }^{\circ}$ 131, 12 de mayo de 1898 , pág. 1. 
darse en "la soberanía y la justicia social". ${ }^{13}$ Právo lidu no informaba mucho sobre los acontecimientos bélicos, pero publicaba frecuentes noticias sobre los precios crecientes de la harina y sobre la falta de material bélico, que despertaba grandes esperanzas en los propietarios de las fábricas productoras de armas. A pesar de una crítica dura sobre la actitud de la "burguesía yankee" que buscaba dinero en la miseria de otro pueblo, los periódicos socialdemócratas consideraban la guerra hispano-americana en cierto sentido como positiva. La victoria de los Estados Unidos (los periodistas de la prensa socialdemócrata no ponían en duda el resultado de la guerra) significaría un nuevo impulso para el desarrollo de la economía estadounidense, que ya representaba un grado más alto de la sociedad capitalista. Según las leyes de la evolución histórica, como opinaban los partidarios checos del marxismo, el progreso del capitalismo culminaría con una revolución socialista precisamente en el país capitalista más desarrollado. De este modo, una guerra victoriosa - con destruir las estructuras viejas- ayudaría al triunfo de la revolución, a la "futura aurora socialista".${ }^{14}$ Por otro lado, también la derrota de España significaría nuevas esperanzas para el socialismo en ese país, ya que "cuanto mayor el desastre, tanto mayor el número de los partidarios del socialismo", ${ }^{15}$ opinaron en Právo lidu.

Fuertemente ideologizada fue también la opinión de la prensa católica, representada ante todo por el periódico Katolické listy (El Periódico Católico). Durante la sublevación en Cuba, sus periodistas no prestaban prácticamente ninguna atención a los acontecimientos en el imperio colonial español. Hasta el 18 de febrero de 1898, Katolické listy no informó sobre la explosión en el crucero "Maine". Sintomático es que la breve noticia fue colocada muy en el fondo del periódico y trató sobre la"causa interna" del accidente. ${ }^{16}$ La tensión entre España y los EE. UU. fue mencionada por primera vez el 10 de marzo de 1898. En el comentario sobre la situación internacional, el periodista consideró que los esfuerzos de España dirigidos a la liquidación del levantamiento en Cuba fracasaron por la ayuda que los Estados Unidos prestaron a la insurrección.

13 Ibídem.

14 “Zápas o primát světa” ("Lucha por la hegemonía mundial”), Ibídem, n. o 222, 12 de agosto de 1898 , pág. 1 .

15 “Zprávy” ("Noticias”), Ibídem, n. 191, 12 de julio de 1898, pág. 3.

16 "Politické zprávy ze zahraničr” ("Noticias políticas del exterior"), Katolické listy, vol. II, n. ${ }^{\circ}$ 50, 18 de febrero de 1898 , pág. 5 . 


\section{JOSEF OPATRNÝ}

“...el embajador en Cuba Lee apoya con todas las medidas a los insurrectos y la pobre España no puede desterrarlo sin arriesgar la declaración de la guerra. La agobiada España debe soportar todo de parte de los yankees para mantener la paz".17

Entre la creciente cantidad de noticias sobre el progreso de los acontecimientos en la segunda mitad de marzo y la primera mitad de abril, Katolické listy subrayó el interés de España por solucionar la situación pacíficamente, repitiendo que la actitud de los Estados Unidos difería sustancialmente. La campaña del interés a favor de los cubanos sufrientes no era más que un chantaje:

"Todo el grupo que obliga al presidente a declarar la guerra no es numeroso, pero sí muy poderoso por su dinero. Y como no tiene en la mente otra cosa que cómo multiplicar su riqueza, no tiene asco en provocar la guerra". ${ }^{18}$

A mediados de abril, los autores de Katolické listy reflexionaron sobre el contexto más amplio de los acontecimientos. ¿Qué significaría la derrota de España?, preguntaban repetidamente. La respuesta rezaba: desalojar su posición de potencia mundial y debilitar la raza romana. "La derrota de Francia, otra de Italia, y ahora la de España - y el nuevo triunfo de la raza germana, la nueva altivez, etc...". ${ }^{19}$ De la misma premisa partió también el autor del comentario publicado el 10 de mayo, que llamó a los Estados Unidos "el gigante creciente". Según este periodista, casi todo el mundo apoyaba a España, y si los Estados Unidos con la Gran Bretaña ocuparan las Filipinas, amenazaría una guerra mundial y una gran explosión social. ${ }^{20}$ En aquel tiempo, la guerra hispano-norteamericana tenía ya su firme lugar en la primera página del periódico. Títulos como "La humanidad 37: el azúcar 51", ${ }^{21} \mathrm{o}$ "Los cazadores del oro en la sangre humana" ${ }^{22}$ expresan claramente el contenido y la opinión de los autores sobre los Estados Unidos y su papel en Cuba. Para el autor del primer artículo, los americanos continuaban en la isla su vieja política:

17 "Ku světové situaci" ("En torno a la situación mundial”), Ibídem, n. ${ }^{\circ}$ 68, 10 de marzo de 1898 , pág. 1.

18 "Politické zprávy ze zahranič̌”" ("Noticias políticas del exterior"), Ibídem, n. ${ }^{\circ} 98,10$ de abril de 1898 , pág. 3 .

19 "Ku světové situaci" ("En torno a la situación mundial"), Ibídem, n. ${ }^{\circ}$ 105, 17 de abril de 1898 , pág. 1.

20 "Vzrůstající olbr̆m" ("Un gigante creciente”), Ibídem, n. ${ }^{\circ} 128,10$ de mayo de 1898, pág. 1.

21 "Lidskost 37 - cukr 51" ("La humanidad 37 : el azúcar 51"), Ibídem, n. ${ }^{\circ}$ 107, 19 de abril de 1898 , pág. 1. 
"Toda la historia de la isla de Cuba no es, probablemente, sólo una acusación a España, como generalmente se presenta ahora, sino que es también una acusación a los Estados Unidos que aprovechaban cada oportunidad para provocar a los cubanos contra España. Un esbozo breve de la historia de esta tierra fértil basta para convencerse de que los estados americanos no dejaron a los cubanos en paz". ${ }^{23}$

Con toda una serie de errores, el autor sigue esbozando la historia de la colonia subrayando su "dulce" riqueza:

"A los capitalistas de América del Norte no basta su trigo, tocino y algodón, ellos buscan una nueva comodidad para "su" industria y por eso la querían comprar primero, después ganar por convencimiento y ahora quieren apoderarse de ella por la violencia bajo la máscara de la liberación". ${ }^{24}$

Rechazando las afirmaciones sobre las crueldades de los españoles, el autor pide que se tome en cuenta el tratamiento de los indios por parte de Estados Unidos llamándolo la vergüenza del ilustrado siglo decimonónico:

"La justicia pide reconocer, que a América (compréndase: a los Estados Unidos, nota del autor) no la dirige el amor a la humanidad sino el amor a la ganancia. El curso de la humanidad es más bajo que el del azúcar”. ${ }^{25}$

El conflicto entre España y los Estados Unidos no fue para Katolické listy solamente un choque entre esos dos países, sino también una controversia entre la potencia americana y toda Europa. Mencionando los méritos históricos de España en la defensa del continente contra la invasión del Islam, el autor concluye su comentario categóricamente: "La diplomacia europea tiene ojos y hace como si no viera que la victoria de España sería la victoria de Europa y viceversa". ${ }^{26}$

Volviendo al papel religioso de España en el mundo, el autor de otro artículo en Katolické listy se refiere a la guerra como resultado de la conspiración masónica contra el país católico. No solamente todos los partidarios de la independencia en Cuba, sino también todos los miembros de la administración colonial que aportaron a la situación lamentable de España, pertenecían a las logias masónicas. ${ }^{27}$ La causa religiosa estaba también en

22 "Lovci zlata v lidské krvi" ("Los cazadores del oro en la sangre humana"), Ibídem, n. ${ }^{\circ}$ 115, 27 de abril de 1898 , pág. 1 .

23 "Lidskost...."

24 Ibídem.

25 Ibídem.

26 "Lovci zlata ..."

27 "Glossy ku španèlsko-americké válce" ("Glosas en torno a la guerra hispano-americana”), Katolické listy, vol. II, n. ${ }^{\circ} 136,19$ de mayo de 1898, pág. 1. 
el centro de interés del periódico católico al hacerse la pregunta por el motivo de la guerra en el extenso artículo "¿Quién causó la guerra hispano-americana?" Esta guerra, "una de las más frívolas en la historia", ${ }^{28}$ la provocaron los periódicos estadounidenses, ante todo el periódico del "judío ruso" Pulitzer y su competidor, "hijo del millonario de California" Hearst. Esa combinación promovió una campaña probélica en toda la sociedad y la fiebre bélica aplastó a los críticos de los planes aventureros.

Después de la derrota de la flota española en la Bahía de Santiago de Cuba, el resultado de la guerra estaba claro para Katolické listy. "Un coloso surge de los dos océanos", ${ }^{29}$ previno el autor del artículo. "Con la anexión de las islas más importantes del Caribe a los Estados Unidos aumentará tanto su influencia en el mundo que la vieja Europa empieza a temblar. Ya comienza a pensar en aislarse de América" ${ }^{30}$ Los EE. UU. orientarán su atención a Asia y al continente americano - añadía - y la interrupción de las relaciones entre esta potencia y Europa, ante todo en la esfera comercial, traerá a este continente peligros insospechados. La industria europea no puede existir sin posibilidades exportadoras, por lo cual las potencias buscan ganarse sus partes del mundo. No obstante, el gigante de los dos océanos puede preparar una catástrofe para la vieja Europa. "La derrota de España significa un desastre para Europa. Ahora ya es muy tarde para detener a este gigante", ${ }^{31}$ concluía el articulista.

También Národní politika, interesándose en el conflicto entre España y los Estados Unidos, subrayó la importancia de este fenómeno para la sociedad checa. En las primeras informaciones el periódico mantuvo una posición neutral esperando la victoria de la potencia americana:

"No es posible continuar en la posesión de Cuba. Caerá en las manos de los EE.UU., a los que pertenece, como una manzana madura. Solamente que este hecho terminará con una tensión, que enseguida por la guerra o por el tratado de paz ...". ${ }^{32}$

No obstante, en los artículos se manifestó la postura de reserva hacia el país llamado en las páginas de Národní politika "el imperio de los millo-

28 "Kdo způsobil španèlsko-americkou válku?” (“¿Quién causó la guerra hispano-americana?"), Ibídem, n. ${ }^{\circ} 139,22$ de mayo de 1898, pág. 1.

29 "Kolos vynořje se ze dvou oceánû" ("Un coloso surge de dos océanos"), Ibídem, n. ${ }^{\circ}$ 184, 7 de julio de 1898, pág. 1 .

30 Ibídem.

31 Ibídem.

32 "Rozhodná chvíle" ("El momento decisivo"), Národní politika, vol. XVI, n. ${ }^{\circ}$ 88, 29 de marzo de 1898 , pág. 1 . 
narios". Según este periódico, para España el conflicto no tenía ninguna salida, ni la victoria en la guerra con los norteamericanos, que Národní politika tenía por imposible, podría resolver la situación en la colonia insurrecta. Por eso había que observar los resultados de la guerra desde un ángulo general. "La guerra siguiente es la de América y Europa", ${ }^{33}$ y tendría una gran importancia para los intereses económicos europeos. Aun sin hablar sobre las pérdidas del comercio durante el conflicto bélico, la anexión de Cuba a los EE. UU. perjudicaría ante todo a los países agrícolas europeos. El avance de la industria azucarera cubana, en las manos de los agresivos empresarios estadounidenses, podría liquidar "el último asilo de los agricultores nuestros, es decir la producción azucarera europea". ${ }^{34}$ Las informaciones sobre los acontecimientos de las cercanías de Santiago de Cuba inspiraron a Národní politika a desarrollar sus consideraciones de mediados de abril:

\begin{abstract}
"Los resultados prácticos de los vencedores estadounidenses no son favorables ni para nosotros, ni para otras naciones europeas. Especialmente Cuba, en manos de los americanos, llegó a ser sensible por su competencia también para nosotros en Bohemia y Moravia. Allí producen azúcar en condiciones muy propicias y la mayor parte de la isla puede convertirse en plantaciones cañeras cuya producción baratísima podría tener influencia fatal en la caída de los precios". ${ }^{35}$
\end{abstract}

Según la opinión de Národní politika, la causa real de la intervención estadounidense en la guerra de España contra sus colonias sublevadas eran las razones económicas. El único resultado positivo del conflicto para Europa era de tipo didáctico: "Para las naciones europeas, la España decadente era un aviso de hasta donde lleva a las naciones la escasez de esfuerzo, de trabajo y fervor". ${ }^{36}$

El único periódico importante que simpatizó claramente con los Estados Unidos fue Národní listy. Durante los primeros meses del año 1898 aportó sólo noticias informativas y en abril aparecieron los primeros comentarios. Národní listy apreció la intervención americana como una ayuda a la nación cubana comparando esta acción con la guerra de Rusia contra el imperio turco en los Balcanes, presentada como el apoyo a la

33 "Válka americko-španèlská a zájmy evropské” ("La guerra americano-española y los intereses europeos"), Ibídem, n. ${ }^{\circ} 106,17$ de abril de 1898, pág. 1.

34 Ibídem.

35 Ibídem.

36 Ibídem. 
lucha de los búlgaros contra la opresión tiránica. Las actividades de los Estados Unidos no significaban la anexión, sino una guerra por "la liberación de un pueblo pobre, oprimido por un gobierno ajeno, inhumano y bárbaro". ${ }^{37}$ Considerando la guerra como un conflicto entre el tradicionalismo español y la modernidad estadounidense, el autor no ocultó su fe y esperanza en la victoria de la segunda. Cada número del periódico desde mayo a junio traía los ecos de las capitales europeas y americanas sobre el transcurso de la guerra, las comparaciones de la economías, flotas y ejércitos de los participantes del conflicto y la crítica de la política colonial española, presentando a España como símbolo del catolicismo y de los regímenes reaccionarios del viejo mundo. Národní listy mencionaba repetidamente la participación de los emigrantes checos en la guerra y la ayuda prestada a la nación cubana que luchaba por su independencia.

Después de las noticias que llegaron desde las Filipinas y las de la victoria de la flota estadounidense en la Bahía de Manila, los periodistas esperaban cada día del mes de junio la misma noticia desde Santiago. El 16 de julio comentaron la caída de esta ciudad como fin de la guerra, comparándolo una vez más con los Balcanes y con la caída de Plevno y llamándolo “...fin del orgulloso dominio sobre otras naciones, la cubana y la filipina, y al mismo tiempo, la pérdida de los últimos restos de la potencia mundial, antaño terrible". ${ }^{38}$ La derrota de España significaba también la derrota del militarismo europeo, concluía el autor de ese comentario. Durante agosto, Národní listy cambió de postura para con los cubanos, presentando a los "luchadores por la independencia nacional" de la primera mitad del año 1898 como un grupo de generales y políticos que buscaban la oportunidad de cómo apoderarse del gobierno. Los Estados Unidos tenían en esta situación el deber civilizador de educar a los independentistas en la democracia $\mathrm{y}$, después, entregarles todos los derechos del estado soberano. ${ }^{39}$ No obstante, para Národní listy la guerra había terminado con la caída de Santiago y, salvo excepciones, no aparecieron más noticias ni comentarios sobre el desarrollo de los asuntos ligados con el conflicto y con el tratado firmado en París.

\footnotetext{
37 "Válka americko-španęlská vypovězena" ("La guerra americano-española declarada"), Národní listy, vol. XXXVIII, n. ${ }^{\circ} 111,22$ de abril de 1898, pág. 1.

38 "Pád Santiaga" ("La caída de Santiago"), Ibídem, n. ${ }^{\circ}$ 194, 16 de julio de 1898, pág. 1.

39 Esta opinión aparece también en la memoria del viajero checo Enrique Stanko Vráz, que visitó Cuba en 1897, publicada bajo el título "Santiago de Cuba", en: Národní listy, vol. XXXVIII, n. ${ }^{\circ} 280,11$ de octubre de 1898 , págs. 1-2.
} 
Hay que mencionar también que quizás la mayor autoridad en la problemática del colonialismo español de fines del siglo XIX orientado al caso de las Filipinas y que vivió en Bohemia, Ferdinand Blumentritt, ${ }^{40}$ presentó en aquel tiempo su postura poco positiva frente a los EE. UU. ${ }^{41}$

Después de la declaración de la guerra, en una pequeña imprenta afuera de Praga se publicó el folletito Námo Išká válka šanà alsko-americká (La Guerra naval hispano-americana).$^{42}$ En la introducción, su autor apunta:

"a pesar de que la guerra naval hispano americana resulte, quizás, demasiado lejana para el pueblo checo, no dudo que la gran parte del público checo observará este enfrentamiento con un interés afectuoso por las razones siguientes...”. ${ }_{43}$

La primera de esas razones era la experiencia de la nación checa con la opresión ajena y con la lucha por la libertad. Por eso, los checos podían apreciar la justa lucha de una nación desgraciada sabiendo que se acercaba también el momento en que ellos mismos lucharían contra sus opresores. La segunda razón era el hecho de que en los Estados Unidos vivía una numerosa emigración checa. El autor expresó su opinión de que:

"muchos entusiasmados compatriotas nuestros entrarían en las tropas como voluntarios participando de esta manera en nombre de la libertad en la guerra por los derechos del desdichado pueblo cubano. Naturalmente, los destinos de esos compatriotas-soldados nos interesarán a nosotros en Bohemia". ${ }^{44}$

Por eso, el autor ofreció al lector checo una breve información sobre España, los Estados Unidos y Cuba, para que se pudiera orientar en el conflicto bélico. Informando sobre España mencionó su gran pasado ${ }^{45} \mathrm{y}$-en el capítulo intitulado Historia - ${ }^{46}$ dedicó mucha atención a la colonización de América, criticando la política adoptada para con los nativos y la institución de la esclavitud. Escribiendo sobre las guerras de la independencia

40 Sobre Blumentritt ver Polišenský, Josef: “José Rizal, Ferdinand Blumentritt and Philippine Struggle for Independence”, New Orient, vol. III, Praga, 1962, págs. 33-34.

41 Blumentritt, Ferdinand: "Spaniens innere Kraft" ("La fuerza interior de España"), Bohemia, vol. 71, n. $^{\circ} 102,13$ de abril de 1898, págs. 1-2.

42 J. H.: Námořská válka šanalsko-americká (La guerra naval hispano-americana), Třebíč, s. d., 64 págs.

43 Ibídem, pág. 5.

44 Ibídem, pág. 6.

45 El Reino de España, en la Edad Media el Estado más poderoso y más rico en toda la Europa..., J. H.: Námo ̌šá..., pág. 8.

46 Ibídem, págs. 21-30. 
en América, las atribuía a la inestabilidad en la Península, que las colonias aprovecharon para pedir la igualdad de derechos con la metrópoli. El rechazo de las exigencias de los portavoces de las sociedades en América por parte del gobierno español causó la proclamación de la independencia acompañada por guerras sangrientas que culminaban con la victoria del partido que luchaba en una guerra justa. El autor atribuía también el subdesarrollo de la industria y de la agricultura españolas, entre otras cosas, a la disminución de la población causada por la emigración a América y como consecuencia de las guerras religiosas.

Tras la descripción de España seguían las páginas dedicadas a los Estados Unidos, en las que el autor subrayó el nivel fascinante de la economía estadounidense, mencionando ante todo la industria y el desarrollo del comercio en la segunda mitad del siglo XIX y vinculando los éxitos de la economía con el nivel de la enseñanza. Al inicio del capítulo sobre la historia, el autor compara de manera interesante el mismo proceso de la lucha contra las metrópolis europeas en las colonias americanas de la Gran Bretaña y las de España. A los eventos más importantes en la historia de los EE. UU. pertenecía, según su opinión, la guerra civil, que consideraba como una lucha por la liberación de los esclavos. La admiración que tenía a los Estados Unidos la reflejan las sentencias que concluyen esta parte del folleto:

"La Unión es un país libre, un país de derechos iguales, en el que no existe ni la aristocracia, ni la diferenciación en las capas de la población urbana y campesina. La igualdad política empezó en 1870 y la libertad grande en toda la vida tiene grandes consecuencias en la vida de todos los americanos. Su vida, no encadenada por los hierros y pesadillas, avanza con una rapidez siempre mayor ... Europa no sirve más de modelo para los Estados Unidos los que, en muchos casos, además de ser ejemplo para nosotros llegan a ser hasta un ideal no alcanzable...". ${ }^{47}$

La tercera parte del folleto, dedicada a Cuba, la abría su autor con la opinión de que la isla significaba para la caja estatal española, siempre vacía, una mina de oro que España consideraba lo mejor de todas sus colonias americanas. Su riqueza consistió en la caña de azúcar, en el café y en el tabaco de una calidad extraordinaria. No obstante, la política española en la isla provocó un gran descontento que siempre iba aumentando y que desembocó en algunos alzamientos, el más grande de ellos en el año 1868. La época de las sublevaciones duró hasta el año 1895 cuando se desenca-

47 Ibídem, pág. 49. 
denó una nueva insurrección. Según las palabras del autor del folletito, los españoles que durante meses no lograban liquidar las tropas de los independentistas apoyadas por capas amplias de la población rural y urbana, empezaron con la política de Weyler el programa de reconcentración. El traslado de la población rural desde las regiones insurrectas significaría, según este programa, hambrear a los guerrilleros y, por consiguiente, la victoria sería de los españoles. En este contexto, el autor informó sobre los daños que la población civil sufrió con esta política, ante todo "los ancianos, las mujeres y los niños", refiriéndose a los resultados de la investigación del senador estadounidense Gollinger. "Según las estimaciones de los españoles mismos, al menos 210.000 de esos desdichados fallecieron por hambre. Y si no llega la ayuda de los Estados Unidos, fallecerán aún otros, de tal manera rezaban las noticias mandadas a la Unión". ${ }^{48}$

Dicha política despertó, según la opinión del autor, grandes simpatías hacia los cubanos en los EE. UU. donde "el pueblo" pedía una intervención de su gobierno. Sin embargo, no fue esa reacción del público norteamericano lo que cambió la política de España en la colonia. Hasta el momento en que los españoles "convirtieron la isla floreciente en un desierto de pobreza y de hambre", ${ }^{49}$ no nombró el gobierno madrileño al nuevo capitán general. No obstante, las reformas del general Blanco llegaron demasiado tarde y los insurgentes ya no pedían menos que la independencia. En aquel tiempo de crisis ocurrió la explosión en el crucero "Maine", que aumentó la enemistad del público estadounidense hacia España. Resulta interesante que, si bien el autor checo no atribuye categóricamente la culpa de la explosión a España, ${ }^{50}$ opina que precisamente la explosión impulsó una nueva ola de intervencionismo en la sociedad estadounidense, frenada sin embargo en sus manifestaciones por la postura antibélica del presidente McKinley. En ese mismo tiempo se desencadenó una fuerte campaña antiamericana en España acompañada por las manifestaciones masivas en contra de los Estados Unidos y su presidente: “A ambos gobiernos, el americano y el español, no le quedó otro remedio que fortalecer los ejércitos y preparar la guerra, obligados a ella por las masas indignadas y por la indignación del pueblo". ${ }^{51}$

48 Ibídem, pág. 55.

49 Ibídem, pág. 56.

50 La cuestión de la explosión del "Maine" representó hasta los años sesenta del siglo XX uno de los puntos siempre investigados por los historiadores y periodistas. Parece que el secreto de la explosión la esclareció Rickover, H. G.: How the Battleship Maine Was Destroyed, Washington D. C., 1976. 51 J. H.: Námořská..., pág. 57. 
En esta situación McKinley intentó rebajar una vez más la tensión e impedir el conflicto abierto pidiendo el final de la insurrección en Cuba mediante medidas pacíficas. También el gobierno español mostró su complacencia en acabar con la guerra ofreciendo a los insurrectos el armisticio que, sin embargo, no fue aceptado. Tampoco ayudaron las actividades de la potencias - "el pueblo pedía solamente la guerra". ${ }^{22}$ El Congreso de los Estados Unidos - escuchando esta voz- aceptó la resolución que proclamó el derecho del pueblo cubano a alcanzar la libertad e independencia, rechazó la política española en Cuba pidiendo categóricamente que el ejército español se marchara de la isla y dio al presidente americano los plenos poderes para realizar esta resolución. La firma de McKinley y el envío del ultimátum americano a Madrid significaron la interrupción de las relaciones diplomáticas entre ambos países. El gobierno español no aceptó el ultimátum y la guerra estalló. Después de esta información, el autor del escrito proseguía con un breve análisis del estado de las fuerzas armadas de ambos países y de la economía que, en el caso de España, no despertaba grandes esperanzas. La amenazante bancarrota financiera del gobierno madrileño representó un peligro muy serio para la financiación de la guerra y, al mismo tiempo, la única desventaja sustancial de España en comparación con los EE. UU.

El autor encontró más o menos equilibradas las fuerzas armadas y concluyó esta parte de su información reproduciendo las opiniones de los especialistas presentadas en la prensa. El resultado de la guerra dependería de la calidad de las flotas ya que se efectuaría prácticamente sólo en el mar. En el caso de combates en la tierra firme, transcurrirían - siempre según nuestro autor - en Cuba o en otras islas. La flota americana tenía la gran ventaja en la cercanía de sus bases a los campos de guerra, mientras que los españoles debían cruzar el Atlántico. La circunstancia quizás más importante era el estado financiero de ambos países. También en este caso la situación parecía más ventajosa para los EE. UU. Mientras que sufridas, eventualmente, las primeras derrotas, los americanos podían movilizar sus recursos, el poco éxito de los españoles significaría, con suma probabilidad, "la revolución y la expulsión de la dinastía actual". ${ }^{53}$ El autor mencionó a Don Carlos, quien esperaba su oportunidad, y prevenía que la posible guerra provocada por los carlistas en España podía significar una

52 Ibídem.

53 Ibídem, pág. 64. 
conflagración bélica en toda Europa. En lo que se refería a las simpatías de los gobiernos europeos, diferían fundamentalmente: con la Unión simpatizaban los ingleses, mientras que la mayoría de los franceses e italianos, los alemanes y la Austria oficial (el subrayado es del autor del folletito) apoyaban a España y solamente Rusia mantenía una postura neutral. No obstante, opinó el autor, todos los estados mencionados podrían intervenir en la guerra si los acontecimientos dañaran sus intereses económicos.

El autor concluía su información sobre la guerra presentando su opinión personal acerca del resultado del conflicto:

"La guerra hispano-americana, que es un acto de justicia y de generosidad por ayudar a hombres valientes a defender su libertad en contra de los opresores, terminará sin duda con la victoria de los americanos y con la expulsión de los españoles de Cuba para siempre". ${ }^{54}$

Hicimos constar que el autor de la última relación más extensa sobre la guerra hispano-americana mencionaba repetidamente el interés de la sociedad checa por los destinos de los compatriotas -emigrantes que vivían en los Estados Unidos-durante este conflicto bélico. Precisamente este grupo tuvo un contacto directo con los acontecimientos y la prensa checo-americana observaba con una gran atención el desarrollo en Cuba, las relaciones entre los EE. UU. y España y, más tarde, naturalmente, ante todo los preparativos para la invasión americana de la isla y las operaciones de las tropas norteamericanas en las colonias españolas. Los numerosos periódicos checos ${ }^{55}$ publicados principalmente en Chicago, Nueva York, St. Louis, etc., es decir en los centros donde más se concentraban los emigrantes de los países checos, no siempre presentaban las mismas opiniones que, en muchos casos, incluso diferían sustancialmente.

Podemos dividir esas opiniones en tres grupos básicos. Dos primeros grupos representaban las ideas de los emigrantes "viejos", es decir, de la primera gran ola que había llegado a América en los años sesenta y setenta. Esta emigración, a fines del siglo ya se había compenetrado con la sociedad de su nueva patria en tal medida que no hacía diferencia entre "nosotros" y los americanos, mientras que los participantes de la emigración obrera de la segunda mitad de los años ochenta y del último decenio

54 Ibídem.

55 Sobre esa prensa periódica ver Štédronský, F.: Zahraniǒní krajanské noviny, ăasopisy a kalendář̌ (Los periódicos, revistas y almanaques publicados por los checos naturalizados en el extranjero), Praha, 1958. 
del siglo XIX a menudo se ponían en la oposición, en algunos casos muy aguda, contra los americanos, a quienes identificaban, frecuentemente, con sus patrones. No obstante, el primer grupo resultaba dividido en su postura hacia la guerra hispano-americana por una línea clara, trazada por la religión. A pesar de que solamente una minoría pequeña de la emigración checa fueran personas de una firme convicción católica, los portavoces de ese grupo desarrollaban muchas actividades religiosas y culturales, publicando algunos periódicos influyentes, entre otros el titulado Národ (La Nación) que hasta la segunda mitad de abril de 1898 apoyaba en sus artículos las pretensiones españolas en Cuba subrayando el carácter católico del reino español.

Una posición diferente defendían, sin embargo, los periódicos de mayor circulación en la comunidad checo-americana, es decir los diarios y almanaques publicados por la editorial de August Geringer en Chicago. Geringer representaba a los inmigrantes triunfadores y bien incorporados a la sociedad de su nueva patria. Nació en 1842 en una pequeña ciudad de Bohemia, Beznice, emigrando en el año 1869 a los Estados Unidos. Tipógrafo cualificado, empezó su carrera americana en Chicago vendiendo libros e intentando editar prensa checa. Después de unos principios difíciles, su periódico Svornost (La Concordia) llegó a ser el más grande y más conocido entre la prensa publicada para la comunidad checo-americana. Geringer editaba toda una serie de revistas, almanaques y periódicos cuyos materiales no diferían, naturalmente, de los que presentaba Svornost. Geringer pertenecía a aquella parte considerable de los periodistas y políticos estadounidenses que a pesar de que criticaban la política española en sus colonias, ante todo en Cuba, no simpatizaban en absoluto con la idea de la intervención americana en esa isla temiendo las consecuencias de la guerra, ante todo para la vida económica de los Estados Unidos. Desde 1895, los periódicos de Geringer informaban extensamente sobre los acontecimientos en la isla vecina rechazando muy severamente ante todo la política del capitán general Weyler. ${ }^{56}$

Comparando el tono de los periódicos de Geringer con el de algunos títulos de la prensa americana del editor Hearst, Svornost o Amerikán (El Americano) parecen muy conservadores y cautelosos. Todavía en el tiempo del hundimiento del "Maine" en las cercanías del puerto de La Habana,

56 En este contexto surge, naturalmente, la pregunta ¿en qué medida conoció el autor del folletito Námořská válka šanäsko-americká el contenido de los periódicos de Geringer que circulaban en la sociedad checa, encontrándose al menos en la biblioteca pública de Náprstek, en Praga? 
Amerikán mantenía una posición moderada, mencionando como una de las posibles causas de la catástrofe un accidente a bordo del barco. ${ }^{57}$ No obstante, durante la primavera de 1898 , la postura de los periódicos publicados por la casa editorial Geringer cambió sustancialmente y en abril los periodistas exigían ya la guerra contra España.

En las páginas de Amerikán apareció una consideración curiosa. El autor del editorial ${ }^{58}$ se identificó con la opinión de la mayoría de la prensa estadounidense, considerando la guerra como una lucha por la libertad contra la opresión tiránica. Sin embargo, después hizo un paralelismo histórico: al mencionar el papel negativo de España, el autor escribió sobre el "catolicismo español" en la historia checa —en la Guerra de los Treinta Años y en la batalla de la Montaña Blanca. Este momento parece muy interesante al menos por dos razones: atestigua los buenos conocimientos históricos de los checos, lo que se relacionaba, indudablemente, con la orientación histórica del renacimiento nacional checo, ${ }^{59}$ y demuestra que - a pesar del proceso de asimilación de los emigrantes checos en la sociedad estadounidense, la que precisamente Geringer y su grupo apoyaban y apreciaban - los emigrantes checos mantenían siempre cierta conciencia de una identidad doble, considerándose al mismo tiempo americanos y checos. No obstante, es verdad que la comparación de la situación en el Caribe con la de Europa central apareció ya antes. Hay un testimonio de ello en las memorias de uno de los representantes del movimiento obrero checo, Gustav Habrman, quien en los años noventa buscó asilo en los Estados Unidos. En su libro ${ }^{60}$ dedicó mucho espacio a la descripción de su intento de incorporarse a las tropas de los insurrectos en Cuba en los años 1896-1897, ${ }^{61}$ comparando en un capítulo de sus memorias a Antonio Maceo con el héroe nacional checo del siglo XV, Jan Ž̈zka. ${ }^{62}$

Los periódicos checo-americanos empezaron a publicar también en abril de 1898 las informaciones sobre las reuniones de los emigrantes che-

57 Comp. "Zpráva o Maine" ("Noticia sobre Maine"), Amerikán, vol XXII, n. o 34a, 17 de febrero de 1898 , pág. 7.

58 Ver El editorial, Amerikán, vol. XXIII, n. ${ }^{\circ} 24 \mathrm{a}, 28$ de abril de 1898, pág. 1.

59 Sobre este problema, que ya desde hace largo tiempo atrae la atención de la historiografía checa, véase ante todo Hroch, Miroslav: Social Preconditions of National Revival in Europe, Cambridge 1985.

60 Habrman, Gustav: Z mého ävota (De mi vida), Praha, 1924, 2a ed.

61 Sobre estas actividades ver Opatrný, Josef: “Los checos y eslovacos en los EE. UU. y la guerra contra el colonialismo español en Cuba, 1895-1898”, Ibero-Americana Pragensia, vol. X, Praha, 1976, págs. 211-218

62 Habrman: $Z$ mého..., págs. 259 y sigs. 
cos en Chicago, Nueva York y otras ciudades cuyos participantes propusieron la formación de cuerpos militares, compuestos únicamente de personas de origen checo, para luchar en la guerra hispano-americana. ${ }^{63}$ Incluso los periódicos católicos publicaron en ese tiempo las proclamas siguientes: " $\mathrm{Si}$ no estás limitado por la situación familiar, cógete tu arma y arriba a la lucha por la libertad de la Cuba desgraciada". ${ }^{64}$ Una opinión contraria la defendió el periódico Dänické listy (Diario obrero) publicado por la asociación de obreros de procedencia checa en Nueva York, una de las ciudades en las que esta emigración obrera checa era muy fuerte, formando la misma una parte importante de la población de esa metrópoli. ${ }^{65} \mathrm{El}$ autor del artículo, del 23 de abril, con un título característico de "¿Qué hacer hoy?”, ${ }^{66}$ rechazó decisivamente todas las guerras, advirtiendo que no significaban más que sufrimiento para la población de todos los estratos sociales y un dineral inmenso para los monopolios, enemigos mortales de los intereses de la clase obrera.

Algunos días más tarde, el corresponsal de Delnické listy en Chicago informó a los lectores sobre la reunión de la asociación deportiva Sokol (El Falcón). ${ }^{67}$ En esa reunión se propuso una vez más la formación de un cuerpo checo que participaría en la guerra hispano-americana, lo que el autor de la noticia comentó despectivamente, escribiendo no obstante al mismo tiempo: "Declaro que — por todos esos hechos terribles, cometidos en sus colonias - el castigo ejemplar de la España soberbia sería imprescindible. La historia de las colonias es una historia de sangre, barbarie y

63 Ver, por ejemplo, el artículo "Schưze českých dobrovolníkư" ("Reunión de los voluntarios checos”), Amerikán, vol. XXIII, 28 de abril de 1898, n. ${ }^{\circ} 34$ a, pág. 20.

64 Ibídem, 5 de mayo de 1898, n. $^{\circ} 35$ a, pág. 2.

65 La colonia más numerosa de obreros de procedencia checa existió en ese tiempo en Chicago; no obstante, en esta ciudad actuaban también los portavoces de las capas medias de la misma nacionalidad que, al parecer, influyeron en los sectores obreros de este lugar en el sentido del pensamiento "nacionalista" americano, o sea antiespañol. Fue precisamente en Chicago donde publicaba sus periódicos August Geringer y donde los organizadores de los meetings probélicos desarrollaron sus mayores actividades.

66 "Co dnes?", Dänické listy, 23 de abril de 1898, n. . 24, págs. 180 y sigs.

67 Sokol, fundado en 1867, se convirtió rápidamente de un símbolo puramente deportivo en un símbolo de la vida nacional checa. Los miembros de esta organización desarrollaron muchas acciones culturales, públicas y políticas, acentuando siempre que sus actividades deportivas servían como preparación para el cumplimiento de las tareas "nacionales" en otras esferas. Con motivo de los aniversarios "nacionales" organizaban fiestas, demostrando su voluntad de proteger los intereses de la oprimida nación checa. Sokol contó pronto no solamente con miles de organizaciones que agrupaban una cantidad siempre creciente de miembros en todo el país, sino que tuvo también muchos grupos entre los emigrantes checos de diferentes Estados, que deseaban apoyar los lazos entre la nueva y la vieja patria esperando que de esta manera ayudarían a la destrucción del régimen opresor en Bohemia. Actividades muy fuertes en este sentido desarrollaron precisamente las organizaciones del Sokol en los EE. UU. 
brutalidad" ${ }^{68}$ Un autor anónimo presentó en su artículo en Dénické listy una opinión aún más crítica ${ }^{69}$ Informando sobre los centros de reclutamiento en Nueva York se refirió a los checos que solicitaban el ingreso en las tropas americanas de manera siguiente:

"Además de zapatos llenos de agujeros y algunos trapos, llamados vestidos, no ves en ellos nada más que cuerpo desnudo con estómago violento ... Al mirar a estos desdichados te llega a la mente una idea: ¿No deberían defenderse antes contra los americanos, ya que son ellos los que les roban todo $?^{70}$

La postura crítica de Delnické listy hacia la guerra y hacia los Estados Unidos no cambió durante todo el tiempo del conflicto. En verano, Delnické listy informó sobre la tensión entre el ejército americano en Cuba y los órganos militares de los insurrectos advirtiendo que los EE. UU. introducían en la isla una dictadura militar. La administración y el gobierno estadounidenses "después de la guerra irían a cortar a los cubanos la libertad hasta tal punto que no les quedaría más que una frase de paja". ${ }^{71}$ Observando el cambio de la presentación de los insurrectos cubanos en la prensa y opinión pública estadounidenses, ${ }^{72}$ el corresponsal de Dalnické listy residente en Chicago expresó algunos días más tarde la misma conclusión:

"Mientras que la opinión pública de los anglosajones simpatizaba antes con los cubanos, ahora empieza a dirigirse contra ellos, ya que las velas inglesas de aquí se esfuerzan por presentar el desgraciado pueblo, azotado por el dominio español, como un populacho harapiento y salvaje. Esto no significa otra cosa que el gobierno de los EE. UU. quiere privar a los cubanos de la libertad prometida. No me siento profeta ni político, no obstante, según las circunstancias existentes, opino que los proyectos de libertad fracasarán". ${ }^{73}$

Mientras que la opinión de Dalnické listy quedaba igual, los periódicos checo-americanos más influyentes seguían presentando juicios que

68 Cifra J. F. S. "Carta de Chicago del 16 de mayo de 1898", Delnické listy, 21 de mayo de 1898, n. $^{\circ} 28$, pág. 218.

69 "Z newyorského ovzduš a válečnického cirku" ("Del ambiente neoyorquino y del círco bélico"), Ibídem, 8 de mayo de 1898, n. ${ }^{\circ} 26$, pág. 202.

70 Ibídem.

71 "Rozhledy a náhledy" ("Revistas y opiniones"), Ibídem, 30 de julio de 1898, n. ${ }^{\circ} 38$, pág. 300 .

72 Sobre esta problemática ver Healy, David F.: The United States in Cuba 1898-1902. Generals, Politicians and the Search for Policy, Madison, 1963)

73 Cifra N.: "Novinky z Chicaga 5-6" ("Novedades de Chicago"), Delnické listy, 13 de agosto de 1898, n. ${ }^{\circ} 40$, pág. 305 . 
reflejaban cambios de postura. Durante los primeros meses de la guerra, las simpatías para con los insurgentes cubanos se hacían patentes no solamente en los editoriales y en los artículos de los periodistas sino también en las cartas de los soldados de origen checo que formaban parte de las tropas invasoras estadounidenses en Cuba. Algunos de ellos escribieron sobre sus experiencias de las batallas,$^{74}$ otros dirigieron su atención a los cubanos y a la naturaleza de la isla. František Jeničk, del primer regimiento de Caballería que llegó a Cuba con uno de los primeros transportes, perteneció a los admiradores de los insurgentes subrayando su voluntad de luchar por la libertad hasta la victoria final. En una de sus cartas escribió: "desearía que vieran a los cubanos que, pobres, a pesar de no tener a veces más que la cartuchera, luchan - jóvenes y viejos - con el mismo entusiasmo". ${ }^{75}$ En otra carta mencionó también la situación de los civiles cubanos diciendo: "Conocí a los cubanos y me veo obligado a decir que su estado es horrible ... Están medio muertos de hambre, desnudos por completo ..." ${ }^{76}$

No obstante, después de tomado Santiago de Cuba por los americanos, en el contexto del empeoramiento de las relaciones entre García y los jefes de las tropas estadounidenses apareció la crítica de las tropas insurgentes. El autor del artículo con un título característico ("¿Qué suerte espera a Cuba?") $)^{77}$ expresó sus dudas en lo que tocaba a las capacidades organizadoras de los jefes del ejército cubano y a la eficiencia de los órganos gubernamentales del Estado insurgente. Según la opinión del autor, la administración no debía entregarse a los cubanos antes de tranquilizarse la situación con el fin de asegurar a los comerciantes y empresarios de los EE. UU. condiciones apropiadas para sus negocios. Cuba debía convertirse transitoriamente en un territorio gobernado por la administración estadounidense para poder desarrollarse hacia el fin deseado - es decir, hasta formar un mercado consolidado capaz de absorber productos de los

74 M. Černý describió el primer contacto con las tropas españolas en su carta del 26 de junio de 1898 diciendo: "El día 20 de este mes arribamos a Cuba; sin embargo, de los españoles no había ni señal. Avanzamos, pues, hacia Santiago y en la marcha el cuarto día encontramos aproximadamente 1500 españoles. Empezamos a disparar, y en medio minuto los dispersamos. Matamos a 79, habiendo perdido tan sólo 17 hombres. Ahora seguimos avanzando hacia Santiago; escribiendo esto, no faltan más que 8 millas para llegar." carta de M. Černý del 26 de junio, en: Amerikán, vol. XXIII, 25 de julio de 1898, n. ${ }^{\circ} 46$ b, pág. 1. pág. 11.

75 František Jeníček en carta del 3 de julio. Ibídem, vol. XXIII, 18 de julio de 1898, n. ${ }^{\circ}$ 45b, pág. 5 .

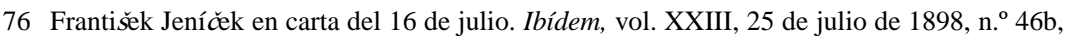

77 “Jaký osud čká Kubu?”. Ibídem, vol. XXIII, 27 de julio de 1898, n. 46b, pág. 3. 
Estados Unidos. No sorprende mucho que Delnické listy criticara severamente este proyecto del protectorado estadounidense en Cuba, si bien limitado a un período breve. Según la opinión expresada en el periódico, tal protectorado reemplazó a la "plutocracia española" y los cubanos no tenían otra posililidad que continuar en su lucha por la libertad "contra los ladrones modernos, los capitalistas". ${ }^{78}$

El análisis de las opiniones de la prensa checo-americana demuestra que la guerra hispano-americana se reflejaba en dichos periódicos de manera similar a las expresadas por la prensa estadounidense. Una parte de los titulares criticaba la invasión y la guerra, no obstante, la mayoría de la prensa mostraba apoyo a la política del gobierno estadounidense. Hay que acentuar que los periódicos checo-americanos no informaban solamente al público checo en los Estados Unidos, sino que servían también como una fuente importante de informaciones directas para los lectores en la "patria vieja".

Sin embargo, resulta patente que la fuente principal de las informaciones y opiniones sobre el conflicto y, naturalmente, también la institución que iba formando la imagen de la guerra hispano-americana en la sociedad checa eran los periódicos y revistas publicados en el país. Para la sociedad y para los periodistas checos, la guerra lejana no era objeto de un interés económico o político directo, no obstante, servía como oportunidad de presentar su postura a un nivel ideológico general. Los liberales apoyaban a los Estados Unidos presentando su sociedad como un símbolo del liberalismo y como defensor del derecho a la lucha por la libertad nacional. Un papel importante para la actitud de la sociedad patriótica checa lo desempeñó también el hecho de que la política oficial austríaca buscaba las posibilidades de cómo apoyar al gobierno de España. Ese país católico encontró también las simpatías en la prensa católica que defendía en España las tradiciones y la religión. Por el contrario, la prensa del movimiento social y obrero criticaba la guerra por principio, ya que perjudicaba los intereses de la mayoría de la sociedad, ofreciendo ganancias solamente al capital. Diferencias marcadas entre las opiniones de los periodistas alemanes y checos, siempre en el marco de la prensa antibélica, hay que buscarlas, ante todo, en la oposición de la prensa socialdemócrata checa en contra del gobierno en Viena que frenaba, en cierta medida, la crí-

78 “Válka skončena?” (“¿La guerra terminada?”) Delnické listy, 20 de agosto de 1898, n. 41, pág. 3. 
tica de la política estadounidense al menos en un punto: allí donde estos críticos de la "guerra del capital" defendían la misma opinión que los católicos, los liberales, etc. Es que escribiendo sobre la guerra hispano-americana, la prensa checa publicada en Bohemia a fines del siglo XIX presentaba la convicción de que el derecho de las naciones a luchar por su independencia, o al menos por la mejora de sus posiciones en la esfera política, cultural y económica, pertenecía a los derechos más importantes para todas las comunidades nacionales. Precisamente este problema atrajo en aquel momento histórico el interés de todos los partidos políticos y capas sociales de la sociedad checa. La guerra hispano-americana llegó a ser, en cierta medida, un argumento más para la discusión política en un país que no tenía ningún interés directo en los resultados del conflicto. 